\title{
Socialization-New Choice of Cultivating Adolescent Badminton Athletes in Sichuan Province
}

\author{
Ming-Min KONG ${ }^{1, a,{ }^{*}}$, Qing LIU ${ }^{1, b}$, Ning QUE ${ }^{1, c}$ and Shang-Wei NIE ${ }^{2, d}$ \\ ${ }^{1}$ Chengdu Sport University, Sichuan Province, China \\ ${ }^{2}$ Chengdu University of Traditional Chinese Medicine, Sichuan Province, China \\ avalen326@hotmail.com, bliuqing@cdsu.edu.cn, '962143419@qq.com, $562485208 @ q q . c o m$ \\ ${ }^{*}$ Corresponding author
}

Keywords: Socialization, Cultivating, Badminton Athletes.

\begin{abstract}
This paper researches the obstacles of the socialization of cultivating adolescent badminton athletes and the measurements by using methods of literature study, questionnaire survey and systematic analysis. Functions of the society and the market in the cultivation of the adolescent badminton athletes should be yielded on the basis of the actual needs of the sustainable development and the system reform of the competitive sports. Functions of the government should be readjusted according to the requirements of the market economy. System innovation should be pushed forward to find new ways of cultivating adolescent badminton athletes.
\end{abstract}

\section{Introduction}

'Socialization' refers to the transition process of natural person to social person. The athlete's free and comprehensive development as well as the spirit of Olympics will be discussed on schedule with the development of the society. In fact, the selection, training and the placement of retired athletes deviate from the "people-oriented" development of athletic sports.

Take Sichuan adolescent badminton athletes as example. Their personalities and relationship with the society are limited by the closed or semi closed specialized training from their childhood. Very few of them get prize in competition while most athletes are eliminated. The problems come from the too simple cultivation subject and training methods.

\section{The necessity of socialization of cultivating adolescent badminton athletes}

This study emphasizes that more social resources should be utilized to change the way of cultivating athletes merely by the government. On one hand, the government should keep financially supporting the project; on the other hand, social forces should gradually become the protagonist.

\section{The inevitable requirement of the market economic system reform}

The economic development of Sichuan Province in recent 5 years maintained a leading domestic average speed. In 2013, the per capita income of urban residents reached 22368 RMB in Sichuan [1] The sports consumption awareness and capacity improves as the labor market and cultural market is constantly expanding. Under the market favor and high social acceptance, the sport of badminton has an extensive market prospect. It offers a suitable external environment for the socialization of cultivating adolescent badminton athletes in Sichuan province.

\section{The inevitable trend of the reform of sports management system}

It carries out a wide range of national fitness activities in Sichuan Province, residents improves the physical fitness. Meanwhile the reform of the sports system in Sichuan should gradually expand, in order to change 'host the sport' into 'administrate the sport' 


\section{The inevitable choice of economic globalization brings to the development of sports undertakings in Sichuan}

Since the end of the twentieth Century, economic globalization has an impact on the traditional international order. The domestic and foreign competitors are in the same market competition, it brings Chinese sports all aspects of effects, whether it's funds, personnel and management method. The new training methods, means and equipment, even foreign coaches and athletic trainers come to Sichuan. To realize the socialization is the inevitable choice to deal with various challenges under the new situation.

\section{The obstacles of the socialization of cultivating adolescent badminton athletes in Sichuan}

Cultivating adolescent badminton athletes in Sichuan is under the Whole - nation System for years. From the historical process of human society, any new change will encounter this or that kind of obstacles. There is no exception with the socialization of cultivating adolescent badminton athletes in Sichuan.

\section{Policy barriers}

1) Eligibility restrictions

Badminton athletes cultivated by socialization cannot register to the higher level of competition such as the province game and the national game. Athletes who register in Provincial sports bureau cannot participate in the competition held by the Education system.

2) The imperfect social security system

Athletes have problems in Job placement, medical insurance, welfare, etc.

\section{Conditional obstacle}

Economic conditions: According to our survey, athletes spend 800 to 1000 RMB on badminton training in Chengdu while athletes in other cities of Sichuan spend 500 to 800 RMB per month. It is a restriction in the process of the socialization of cultivating adolescent badminton athletes if athletes cannot afford the training cost.

Training conditions: 83 percent of athletes think the training conditions cannot be guaranteed without state run training schools. In western counties where they have a higher level of cultivation socialization, family or enterprises sponsor the athletes to hire coaches who choose the training methods and equipment.

\section{The obstacle of system}

With the continuous development of market penetration and occupation, in the sports field of our country, It brings fierce collision between Chinese existing essential attribute of competitive sports management and system and the sports spirit and sports socialization. Therefore, to establish a market, and even the occupation of the requirements of the development of the training system of badminton athletes in Sichuan represent the general trend. However, in the implementation of outstanding athletes training organization and management structure of administrative monopoly and the current cultivation of athlete socialization process, it is a major obstacle in line with international standards and is affecting athletes training process of development. It refers to tha the management system is a highly centralized system, with administrative management and instruction as the basic means, is a kind of management mode suited to the planned economy. In this system, the sports management center and the association is "isomorphism" or "mixed" mechanism. [2] Sichuan badminton sports management center, has a similar functions with enterprises, private associations and government agencies. It makes this civil society groups Association lose their beyond recognition, thus "social development" objectively has become a kind of implementation of the government behavior. In this case it is inevitable for the center to performan goals and interests, to make some obvious unfair rules or limits in the name of association.

In accordance with Chinese traditional management system, the training and selection of athletes are inside the system. Today, the process of cultivating athletes have emerged from the club, family and 
other social organizations. However, this mechanism does not complete the reform. Although the talents cultivation is socialized, we had to enter the old "national selection" system, namely, by participating in the provincial team, participate in the national games, finally enter the national team system. [3]

The 'three level system'---the implementation of sports school, the local team and national team has a long history in China. This system is relatively closed and independent, with a high degree of specialization, concentrate advantage, has made important contributions to the development of Sichuan badminton. But in recent years, its disadvantages are also increasingly apparent, the capital constraint, training and cultural learning disjunction, their re-employment etc. And "socialization" can solve these problems effectively, but it is still controlled by the original system--- in the "registration" and "the right to compete" has a monopoly in the Sport departments of the government at all levels, rather than social groups, individuals and families and businesses.

\section{Suggestions of socialization of cultivating adolescent badminton athletes}

The lack of socialization has become a key problem of restricting and influencing the sustained, healthy development of badminton in Sichuan. For this, we should proceed from actual need of sustainable competitive sports system reform and the development of competitive sports, correctly understand and to properly play the role of society and market in cultivating excellent athletes. In the competitive sports system reform, accelerate institutional innovation, with socialization as the guidance, to explore new ways of cultivating excellent athletes.

\section{The moderate intervention of Sport department}

Moderate intervention of sports department: use policy levers or economic means to adjust the contradiction between supply and demand and structural balance, helps keep the advantage sports reserve talented person troop's stability.

\section{Actively encourage social forces to participate in training, strengthen the relevant laws and} regulations system construction

Sports department should actively guide social forces to participate in the training of elite athletes. Social participation can form another from the production of reserve sports talents to elite athletes pipeline in the present system, increase the total amount of athletic talents and compete with the 'three level system'. In this process, the physical education departments of the government should formulate relevant laws and more perfect, to regulate the cultivation of social forces to participate in elite athletes, the related system establishment and perfection of outstanding athletic talent exchange, so that each culture subject to compete in the same conditions, guarantee of training units reasonable interest returns.

\section{Promote the organic combination of the government Sports Department and Education Department}

'The combination of sport and education' Is a form of sports talent combined with the cultivation of sports system and education system. With the development of athletic sports and the social demand for talents to improve standards, "combined with" simple forms is beyond the sports system and education system of early joint training sports talents of physical education, and gradually to the "combination of form all-round development". [4] In the process of the future implementation of our elite athletes training of the community, to rely on cultivating outstanding athletes in colleges is one of the most convenient and effective way, namely by the ordinary institutions of higher learning as a leader, linking and gradually improve the large, primary school sports talent cultivation mechanism, is the best choice to realize Humanistic Olympic Games gold medal strategy and the training of elite athletes [5].

\section{Acknowledgement}

This research was financially supported by Chengdu Sport University Scientific Research Foundation: 13 YJ06. 


\section{References}

[1] Sichuan Statistics[EB/OL].http://www.sc.stats.gov.cn.

[2] Yang hua. Competitive Sports and the Important Issues of Preparation for the Olympic Games [M].Bei jing: Bei jing Sport University Press,2006, pp36-37.

[3]Taoye. Brain Drain Reveals System Defects, Reserve Personnel Training and Selection of Fracture [N].Yangzi Evening, 2005-03-22.

[4] Yang Zaihuai. The Sports Reserved Talents Cultivation [M].Beijing: People's Publishing Inc., 2006, pp76-83.

[5]Chen Peide. Historical Contribution and Limitation of the Times the National Games Competition System [J]. Zhe jiang Sports Science, 2002(8), pp11-14. 